УДК 616.136-007.256+616.146-005.6

DOI 10.11603/1811-2471.2020.v.i4.11772

\title{
КЛІНІЧНИЙ ВИПАДОК ПОДВОЄННЯ ПРАВОЇ НИРКОВОЇ АРТЕРІЇ, УСКЛАДНЕНИЙ КОМПРЕСІЄЮ ТА ТРОМБОЗОМ ПРАВОЇ НИРКОВОЇ ВЕНИ, ФЛОТУЮЧИМ ТРОМБОЗОМ НИЖНЬОї ПОРОЖНИСТОЇ ВЕНИ
}

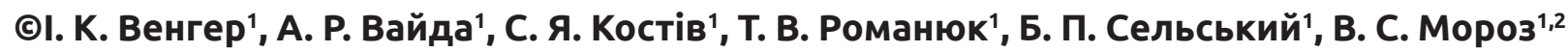 \\ Тернопільський національний медичний університет імені І. Я. Горбачевського МОз Українит \\ Тернопільська університетська лікарня²
}

PЕЗЮмЕ. Пацієнт К. звернувся в Тернопільську університетську лікарню зі скаргами на гематурію та періодичний біль у попереку, які з'явилися протягом останніх двох днів, вперше. При об'єктивному фізикальному обстеженні виявлено пастозність шкірних покривів та виражений набряк обох нижніх кінцівок. Лабораторні показники - загальний, біохімічний аналізи крові, коагулограма та електрокардіограма - без патологічних змін. Наявна макрогематурія. При проведенні цистоуретроскопії патології не виявлено. За даними ультрасонографічного обстеження живота, органів заочеревинного простору, нижніх кінцівок патологічних змін не виявлено. Проведено комп'ютерну томографію з контрастуванням судинного русла органів черевної порожнини, в результаті якої виявлено подвоєння правої ниркової артерії з нетиповим аномальним розташуванням додаткової артерії.

У результаті проведеної діагностики захворювання у пацієнта вдалось встановити вроджену аномалію розвитку артеріальної системи правої нирки, що спричинила компресію правої ниркової вени, її ектазію, венозний стаз крові та явища флебогіпертензії у правій нирці, що, власне, і стало причиною гематурії. Саме венозний стаз і спричинив тромбоутворення із прогресуванням тромбозу на нижню порожнисту вену з флотацією в її просвіт.

Враховуючи явища флотації з поширенням тромботичних мас у нижню порожнисту вену, методом лікування обрано оперативне втручання - тромбектомію з правої ниркової та нижньої порожнистої вен.

КЛючОВІ СлОВА: аномалія розвитку; подвоєння; компресія; тромбоз; флотуючий тромбоз; ниркові артерії; ниркові вени; нижня порожниста вена.

Вступ. Серед аномалій сечовивідних шляхів, аномалії ниркових судин зустрічаються найчастіше - до 70-80\%. У більшості випадків спостерігаються додаткові артерії нижнього полюса нирки, які зміщують і механічно перетискають сечовід, що порушує відтік сечі від нирки, викликаючи ії гідронефротичну трансформацію та інші небажані ускладнення.

Пацієнт К. звернувся в Тернопільську університетську лікарню зі скаргами на гематурію та періодичний біль у попереку. Скарги виникли протягом останніх двох днів, вперше. 3 анамнезу відомо, що пацієнт ліків не отримував, контакту з токсичними, отруйними речовинами не мав, епідеміологічний та інфекційний анамнез не обтяжений.

При об'єктивному фізикальному обстеженні виявлено пастозність шкірних покривів та виражений набряк обох нижніх кінцівок. Лабораторні показники: загальний, біохімічний аналізи крові, коагулограма та електрокардіограма - без патологічних змін. Наявна макрогематурія. При проведенні цистоуретроскопії патології не виявлено. За даними ультрасонографічного обстеження живота, органів заочеревинного простору, нижніх кінцівок, патологічних змін не виявлено. Запідозрено синдром Лускунчика (NCS-Nutcracker syndrome), який проявляється аорто-мезентеріальною компресією лівої ниркової вени внаслідок здавлювання верхньою брижовою артерією, що також маніфестує больовими явищами в попереку і малому тазі з по- явою протеїнурії та гематурії. Проведено комп'ютерну томографію з контрастуванням судинного русла органів черевної порожнини. Виявлено подвоєння правої ниркової артерії з нетиповим аномальним розташуванням додаткової артерії (рис. 1).

Встановлено, що права ниркова артерія (рис. 1. А, В, С) розташована фізіологічно позаду правої ниркової вени, i, судячи із 3D-реконструкції зображення, кровопостачає верхню і середню третини правої нирки. На рисунку 1. D відображено 3D-реконструкцію органів заочеревинного простору з візуалізацією додаткової правої ниркової артерії, що локалізована попереду правої ниркової вени. На цьому ж зображенні показано венектазію правої ниркової вени, явища тромбозу у ній із поширенням на нижню порожнисту вену та флотацією головки тромбу.

У результаті проведеної діагностики у пацієнта вдалось встановити вроджену аномалію розвитку артеріальної системи правої нирки, що спричинила компресію правої ниркової вени та ії ектазію (рис. 2), венозний стаз крові та явища флебогіпертензії у правій нирці, що, власне, і стало причиною гематурії. Саме венозний стаз спричинив тромбоутворення із прогресуванням тромбозу на нижню порожнисту вену з флотацією в її просвіт.

Враховуючи явища флотації з поширенням тромботичних мас у нижню порожнисту вену, ме- 
Огляди літератури, оригінальні дослідження, погляд на проблему, випадок з практики, короткі повідомлення



A



C

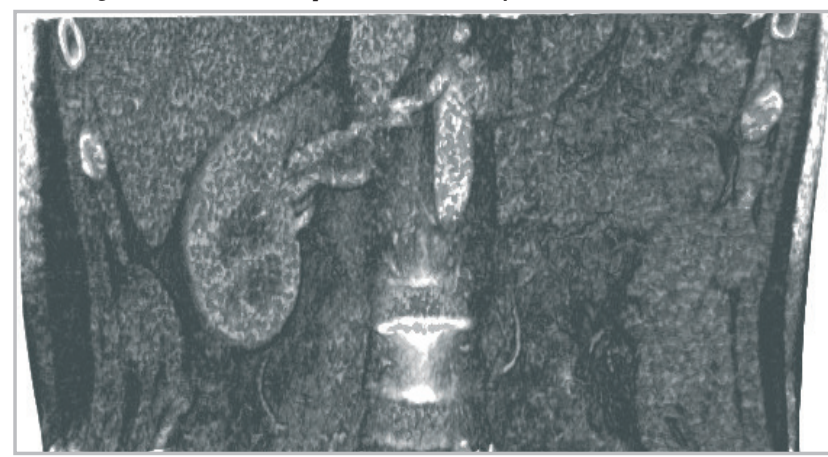

B

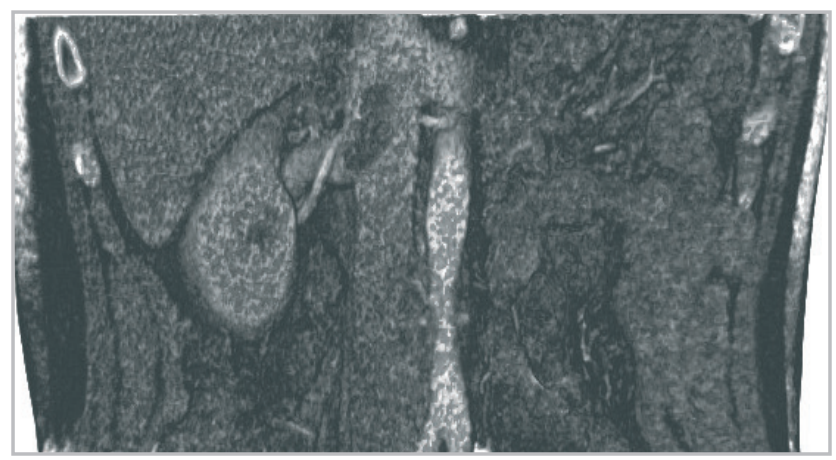

$\mathrm{D}$

Рис. 1. Комп'ютерна томографія органів черевної порожнини. Тривимірна реконструкція зображення: A, B, C- фронтальні пошарові зрізи нормального розташування правої ниркової артерії (позаду правої ниркової вени); D - фронтальний поверхневий зріз додаткової ниркової артерії (попереду ниркової артерії).

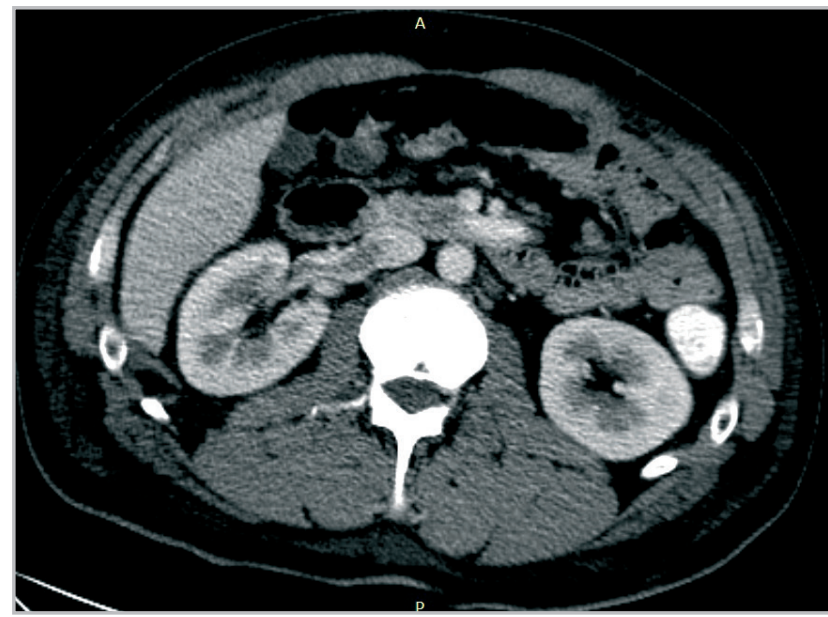

A

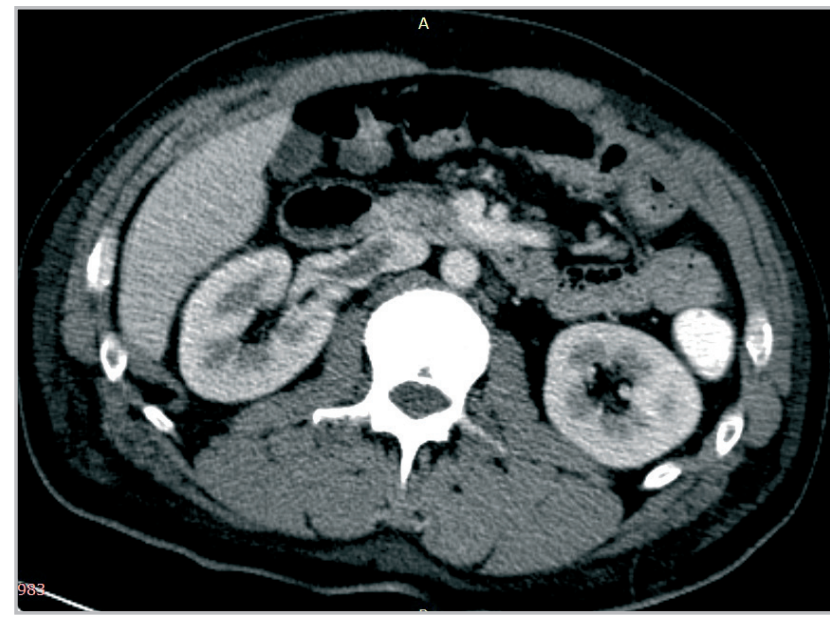

B

Рис. 2. Комп'ютерна томографія живота. Пошарові зрізи. Ектазія правої ниркової вени, тромбоз.

тодом лікування є оперативне втручання - тромбектомія з правої ниркової та нижньої порожнистої вен.

Висновки. 1. Аномалія розвитку артеріальної системи правої нирки, така як подвоєння правої ниркової артерії з нетиповим аномальним розташуванням додаткової артерії, може спричиняти компресію ниркової вени та призводити до її ектазії.
2. Венозний стаз крові у правій нирці у підсумку підвищує явища тромбоутворення, що було причиною тромбозу ниркової вени із поширенням процесу на нижню порожнисту вену і флотацією тромботичних мас у її просвіт.

3. 3 метою запобігання тромбоемболічним ускладненням показано оперативне втручання тромбектомія з правої ниркової та нижньої порожнистої вен. 
Огляди літератури, оригінальні дослідження, погляд на проблему, випадок з практики, короткі повідомлення ЛІТЕРАТУРА

1. Урологія : національний підручник для студ. вищих мед. навч. закладів IV рівня акредитації / С. П. Пасєчніков, С. О. Возіанов, В. М. Лісовий [та ін.] ; за ред. С. П. Пасєчнікова. - Вінниця : Нова Книга, 2013. - 432 с.

2. Глыбочко П. В. 3D-технологии при операциях на почке: от хирургии виртуальной к реальной / П. В. Глыбочко, Ю. Г. Аляев. - М. : ГЭОТАР-Медиа, 2014. - 296 с.

3. Campbell-Walsh urology. Eleventh edition / A. Wein, L. Kavoussi, A. Partin, C. Peters. - Elsevier, 2016. - 4901 p.

4. Smith's textbook of endourology / A. D. Smith, G. Preminger, G. H. Badlani, L. R. Kavoussi Eds. - 3rd ed. John Wiley \& Sons, 2012. - 1838 p.

\title{
REFERENCES
}

1. Pasyechnikov, S.P., Vozianov, S.O., Lisovyy, V.M. Kostev, F.I., Lyulko, O.O., Sarichev, L.P., ..., \& Shostak, M.V. (2013). Urolohiia: natsionalnyi pidruchnyk dlia stud. vyshchykh med. navch. zakladiv IV rivnia akredytatsii [Urology: a national textbook for students of higher medical educational institutions of the IV level of accreditation]. S. P. Pasyechnikova ed. Vinnytsia: Nova Knyha [in Ukrainian].

2. Glybochko, P.V., \& Alyayev, Yu.G. (2014). 3D-tekhnologii pri operatsiyakh na pochke: ot khirurgii virtualnoy $k$ realnoy [3D technologies for kidney surgery: from virtual to real surgery]. Moscow: GEOTAR-Media [in Russian].

3. Wein, A., Kavoussi, L., Partin, A., \& Peters, C. (2016). Campbell-Walsh urology. Eleventh edition. Elsevier.

5. A systematic review on management of nutcracker syndrome / C. A. Velasquez, A. Saeyeldin, M. A. Zafar [et al.] // J. Vasc. Surg. Venous Lymphat. Disord. - 2018. Vol. 6 2). - P. 271-278.

6. Polguj M. An unusual case of left venous renal entrapment syndrome: A new type of nutcracker phenomenon? / M. Polguj, M. Topol, A. Majos // Surg. Radiol. Anat. 2013. - Vol. 35 (3). - P. 263-267.

7. Vascular surgery / L. Hands, M. Murphy, M. Sharp, S. Ray-Chaudhuri. - NY. : Oxford University Press, 2007. $471 \mathrm{p}$.
4. Smith, A.D., Preminger, G., Badlani, G.H., \& Kavoussi, L.R. (Eds.)ю (2012). Smith's textbook of endourology. 3rd ed. John Wiley \& Sons.

5. Velasquez, C.A., Saeyeldin, A., Zafar, M.A., Brownstein, A.J., \& Erben, Y. (2018). A systematic review on management of nutcracker syndrome. J. Vasc. Surg. Venous Lymphat. Disord., 6 (2), 271-278.

6. Polguj, M., Topol, M., \& Majos, A. (2013). An unusual case of left venous renal entrapment syndrome: $A$ new type of nutcracker phenomenon? Surg. Radiol. Anat., 35 (3), 263-267.

7. Hands, L., Murphy, M., Sharp, M., \& Ray-Chaudhuri, S. (2007). Vascular surgery. New York: Oxford University Press.

\section{КЛИНИЧЕСКИЙ СЛУЧАЙ УДВОЕНИЯ ПРАВОЙ ПОЧЕЧНОЙ АРТЕРИИ, ОСЛОЖНЕННЫЙ КОМПРЕССИЕЙ И ТРОМБОЗОМ ПРАВОЙ ПОЧЕЧНОЙ ВЕНЫ, ФЛОТИРУЮЩИМ ТРОМБОЗОМ НИЖНЕЙ ПОЛОЙ ВЕНЫ}

\author{
○И. К. Венгер ${ }^{1}$, А. Р. Вайда ${ }^{1}$, С. Я. Костив ${ }^{1}$, Т. В. Романюк ${ }^{1}$, Б. П. Сельский ${ }^{1}$, В. С. Мороз ${ }^{1,2}$ \\ Тернопольский национальный медицинский университет имени И. Я. Горбачевского МОз Украины ${ }^{1}$ \\ Тернопольская университетская больница
}

РЕзюМЕ. Больной К. обратился в Тернопольскую университетскую больницу с жалобами на гематурию и периодические боли в пояснице. Жалобы возникли за последние два дня впервые. При осмотре у больного обнаружен отек конечностей. Лабораторные показатели - общие анализы крови и электрокардиограмма - без патологических изменений. При проведении цистоуретроскопии патологии не выявлено. По данным УзИ брюшной полости, забрюшинных органов, нижних конечностей патологических изменений не выявлено. Выполнена компьютерная томография с контрастированием сосудов органов брюшной полости. Выявлено удвоение правой почечной артерии с атипичным патологическим расположением добавочной артерии.

В результате проведенной диагностики у пациента удалось установить врожденную аномалию развития артериальной системы правой почки, вызвавшую сдавление правой почечной вены, ее эктазию, венозный застой крови и явления флебогипертензии в правой почке, которое, собственно, и вызвало гематурию. Венозный застой вызвал тромбоз с прогрессированием тромбоза в нижнюю полую вену с флотацией в ее просвет.

Учитывая факт флотации с распространением тромботических масс в нижнюю полую вену, методом лечения избрано оперативное вмешательство - тромбэктомия из правой почечной и нижней полой вен.

КЛючЕВЫЕ СЛОВА: аномалия развития; удвоение; компрессия; тромбоз; флотирующий тромбоз; почечные артерии; почечные вены; нижняя полая вена. 
Огляди літератури, оригінальні дослідження, погляд на проблему, випадок з практики, короткі повідомлення

\title{
CLINICAL CASE: DOUBLING OF THE RIGHT KIDNEY ARTERY, COMPLICATED \\ BY COMPRESSION AND THROMBOSIS OF THE RIGHT KIDNEY VEIN, FLOATING THROMBOSIS OF THE VENA CAVA INFERIOR
}

 \\ I. Horbachevsky Ternopil National Medical University' \\ Ternopil University Hospital ${ }^{2}$
}

SUMMARY. Patient K., apply to Ternopil University Hospital with complaints of hematuria and intermittent low back pain. Complaints were noted in the last two days, for the first time. During examination of patient limb edema was detected. Laboratory indexes: general blood tests and electrocardiogram - without pathological changes. Cystourethroscopy, no pathology was detected. According to ultrasonographic examination of the abdomen, retroperitoneal organs, lower extremities, no pathological changes were detected. Computed tomography with contrast of the vessels of the abdominal organs was performed. Doubling of the right renal artery with an atypical abnormal location of the accessory artery was revealed.

As a result of the conducted diagnosis of diseases the patient was able to establish a congenital anomaly development of the arterial system of the right kidney which caused compression of the right renal vein, and ectasia, venous stasis of blood and the phenomenon of phlebohypertension in the right kidney, which, in fact, caused hematuria. Venous stasis caused thrombosis with progression of thrombosis to the vena cava inferior with flotation into the lumen.

Considering the fact of flotation with the spread of thrombotic masses in the inferior vena cava, the method of treatment is surgery - thrombectomy of the right renal and vena cava inferior.

KEY WORDS: development anomaly; doubling; compression; thrombosis; floating thrombosis; kidney artery; renal veins; vena cava inferior.

Отримано 14.10 .2020 